\title{
World Largest Outcrop of Pure Hydrate on the Seafloor
}

\author{
Akira Takeuchi ${ }^{1}$, Jin Zhang ${ }^{1}$, Urumu Tsunogai ${ }^{2}$, Kiyoyuki Kishimjoto ${ }^{3}$, Kiyokazu Nishimura ${ }^{3}$, \\ Mitsugu Kitada ${ }^{4}$, Shunsuke Saegusa ${ }^{2}$, Takuya Maekawa ${ }^{1}$, Yuri Minamino ${ }^{1}$, \\ Yuki Oike ${ }^{1}$ and Morihumi Takaesu ${ }^{5}$
}

\begin{abstract}
Sea bottom exposure of a sherbet hydrate was not unusual as famous as in the Hydrate Ridge along the Oregon coast of United States. During the NT06-19 cruise Leg2 of R/V Natsushima and Hyper-Dolphin at the sea area southwest off the Sadogashima Island in the central Japan Sea, a fantastic outcrop of exact crystalline methane hydrate was discovered and exhumation of the world's largest scale was observed by the submersible investigation. It means that tectonic activity and related methane plume of this area is so active that formed a mud volcano with a conduit topped by such an outcrop. It is expected that the formation mechanism of the solid methane hydrate layer will be distinctly clarified by synthesizing our analytical results of each field concerning the cruise.
\end{abstract}

In search of information about the relationship between 'Tectonics and the mechanisms involved in the formation of hydrocarbon resources', the research cruise NT06-10 carried out a multi-purpose remote-operating-vehicle (ROV) survey which has located the world largest outcrop composed of layers of solid pure methane hydrate. The outcrop is directly exposed on the seafloor at a depth of $980 \mathrm{~m}$ in the Japan Sea off Toyama and Niigata Prefectures, Japan. The thickness of the strata of methane hydrate, which was observed and measured by the ROV, is estimated to be at least $4 \sim 5 \mathrm{~m}$. Several fallen blocks of pure hydrate ranging from one to several meters in length were also observed around the foot of the outcrop wall.

The Joetsu knoll, southwest of Sadogashima Island, lies in the area called "Sado Nansei-oki", a national drilling exploration site for hydrocarbon resources of the Japanese Ministry of Economy, Trade and Industry (METI). The site is situated in the Toyama Trough which is the tectonic boundary between the Northeast and Southwest Japan $\operatorname{arcs}^{1}$, precisely on the convergent plate boundary between Okhotsk and Amur plates ${ }^{2}$. On September 21, 2006, the researchers utilized the research vessel "Natsushima" and the ROV "Hyper Dolphin" belonging to the Japan Agency for Marine-Earth Science and Technology (JAMSTEC), from which it carried out submersible dive No.604 in the central part of the knoll.

The ROV began surveying at a flat depression (986m) and promptly proceeded to a target hill previously located utilizing a multi-narrow beam swath survey system installed in the mother vessel. The hill is one of the highest crests of the knoll and responds to acoustic beams by displaying a columnar echo, presumably corresponding to strong venting of gaseous seepage. In addition, investigation using a side-scan-sonar and sub-bottom profiler system installed on the ROV was also performed to acquire acoustic images of the survey site. The hill is situated at the southern edge of a larger plateau. The foot and hillside were of a muddy, sedimentary composition. A large number of calcareous rubble formed by concretion was clearly visible around the hilltop. Many red queen crabs, large numbers of ball-shaped sponges and many snails were crowded in small mounds covered with microbial mats fringed by tiny chimneys.

Then, after we installed a marker on top of the target hill (972m), we encountered a pit crater similar to that of a mud volcano. The crater rim was a 9-meter deep ellipsoid with a maximum diameter of $20 \mathrm{~m}$ in a NE-SW orientation. The ROV descended onto the crater bottom (980m; water temperature $0.2^{\circ} \mathrm{C}$ ) and performed observations and

\footnotetext{
1 University of Toyama

2 Hokkaido University

3 Geological Survey of Japan /AIST

4 Enoshima Aquarium

5 Nippon Marine Enterprises Ltd.
} 
water sampling. The lower half of the inner crater wall consisted of minute impacted methane hydrate partially covered by microbial film or by dust and a thin layer of talus. The hydrate layers seemed rigid enough to form steep cliffs and caves. By zooming in using a hi-vision camera, two types of hydrate were recognized: one was massively transparent and the other demonstrated stripes of semi-transparent and white-colored seams of hydrate. Since it was quite difficult to take a sample directly from the cliff, we managed to collect a slab $(100 \mathrm{~cm} \times$ $80 \mathrm{~cm} \times 25 \mathrm{~cm}$ ) which had fallen from right above the immediate cave.

In order to recover the sample, we raised the ROV with the slab being held by the manipulators. On the trip to the surface the slab seemed stable, even at the expected decomposition point around $350 \mathrm{~m}\left(1.0^{\circ} \mathrm{C}\right)$. Obvious sparkling commenced at about $200 \mathrm{~m}\left(4.5^{\circ} \mathrm{C}\right)$ followed by furious bubbling and fracturing. At a depth of around $70 \mathrm{~m}$ $\left(17.0^{\circ} \mathrm{C}\right)$, the fragments which best avoided fusion arrived at the surface of the sea $\left(23.9^{\circ} \mathrm{C}\right)$, and three pieces were recovered for analysis. The specimens also evidence alternating semitransparent and milky seams that may correspond to methane hydrate of high purity and containing of water, respectively. This operation suggests that, from a sea floor depth of $1,000 \mathrm{~m}$, a pure hydrate lump might arrive at the sea surface as solid and then vaporize into the atmosphere, if it were of sufficient volume when it left the bottom.
The sea bottom exposure of sherbet hydrate on the hydrate ridges off Oregon, in the Pacific coast of North America is well known ${ }^{3}$. Contrastingly, the discovered outcrop of methane hydrate on the Joetsu knoll in the Japan Sea, as well as the recovered hydrate samples, was completely solid and of minute crystalline structure. The Joetsu-type hydrate demonstrates that the upwelling of methane gas from the reservoir to the seafloor is quite vigorous in the area. Moreover, because of its high buoyancy, it might rise and ceil up through the upper limit of stability onto the sea surface, if, for example, a large earthquake were to occur. An integrated study of seabed topography, acoustic imaging, geochemistry and deep sea biology is necessary in order to elucidate to better understand total process and mechanism concerning the formation of the thick layer of pure methane hydrate, the environmental evolution of cold seepage, and the related biological community on the bottom of the sea.

\section{References}

1) Okamura, Y. Marine Geology Map Series no. 59 (CD) ( Geological Survey of Japan; 2002)

2) Takeuchi, A. Earth Planets Space 56, 1261-1269; 2004

3) Shipboard Scientific Party ODP Leg 204 Preliminary Report (Ocean Drilling Program; 2002)

(Received December 15, 2006)

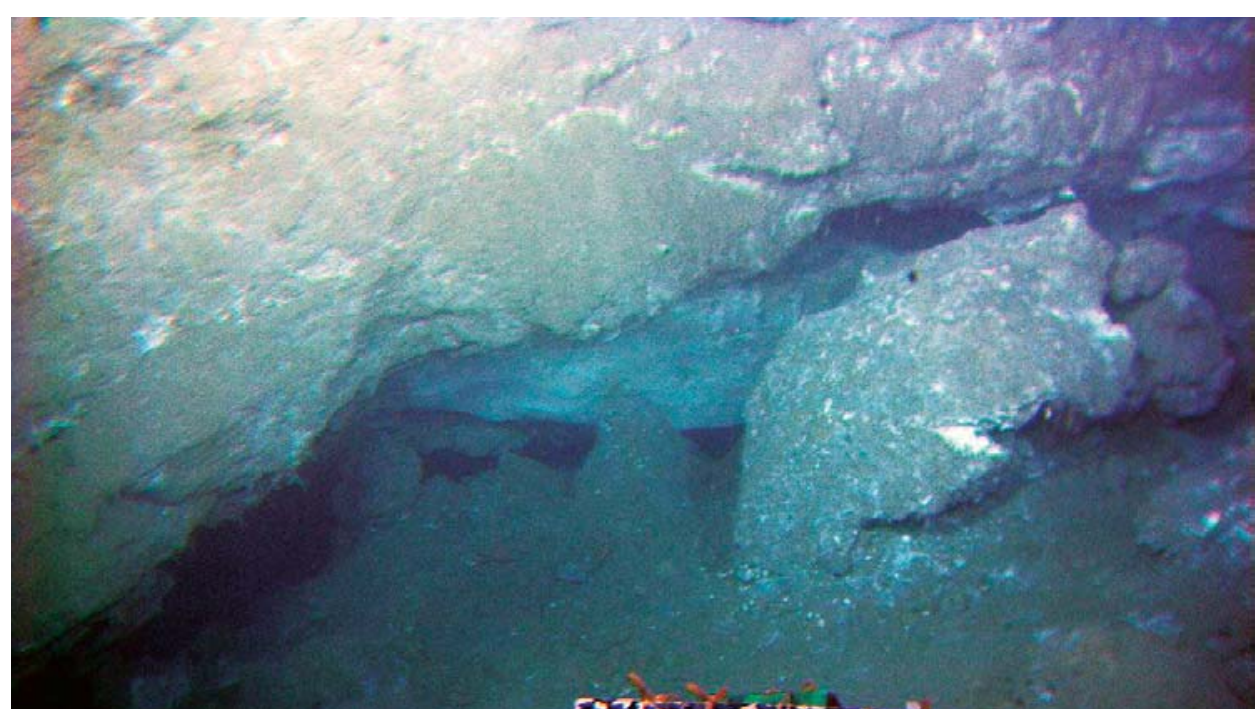

Figure 1: Semitransparent block occupies the cave beneath the layered hydrate outcrop. 


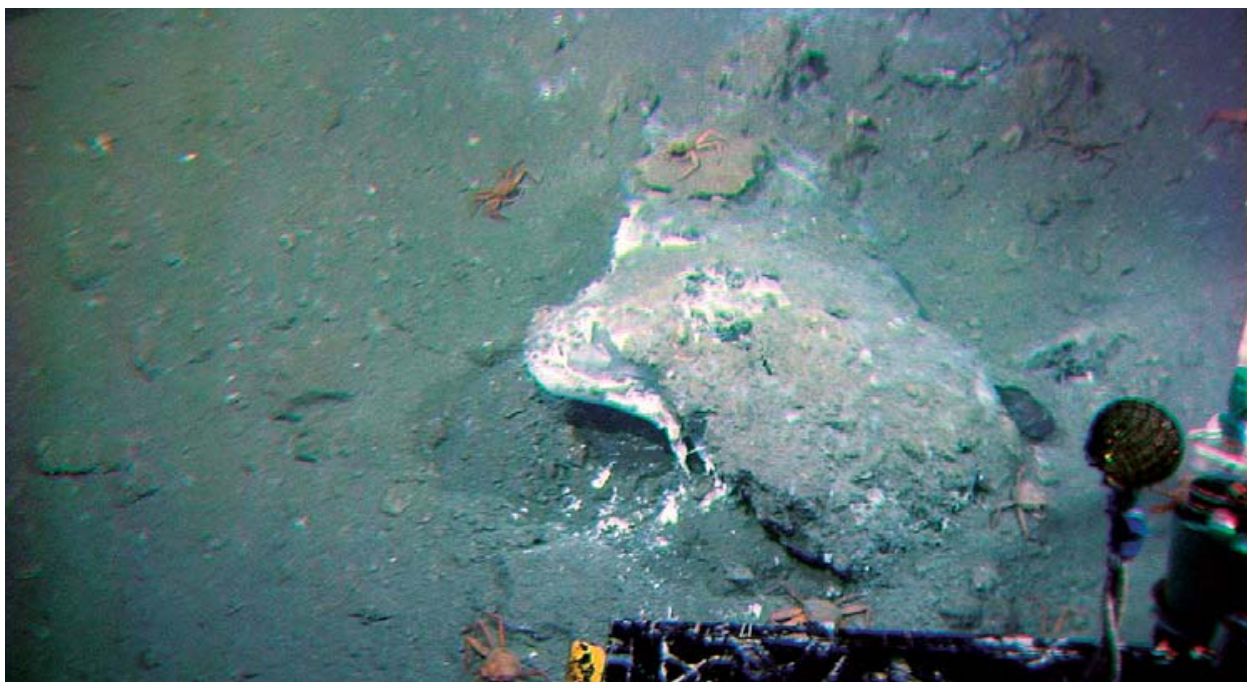

Figure 2: $1 \mathrm{~m}$ size of solid hydrate slab fallen in front of the cave.

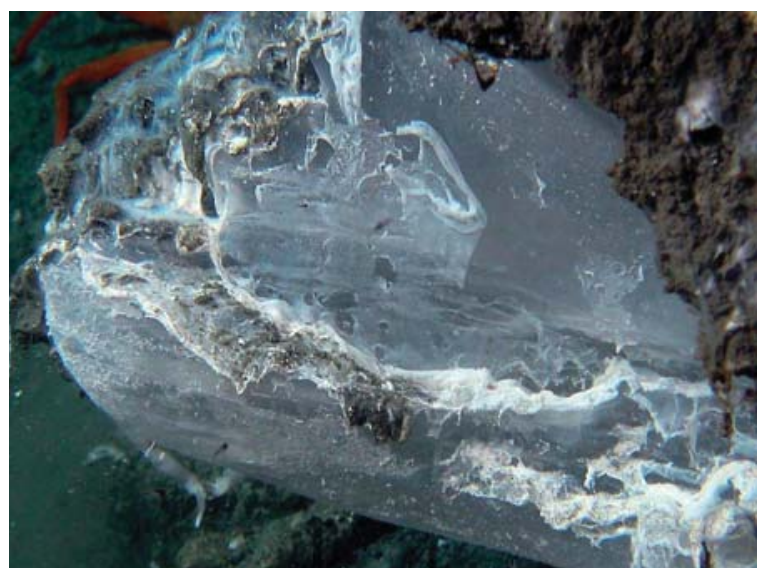

Figure 3: Closed-up photo of the striped hydrate slab with microbial coating.

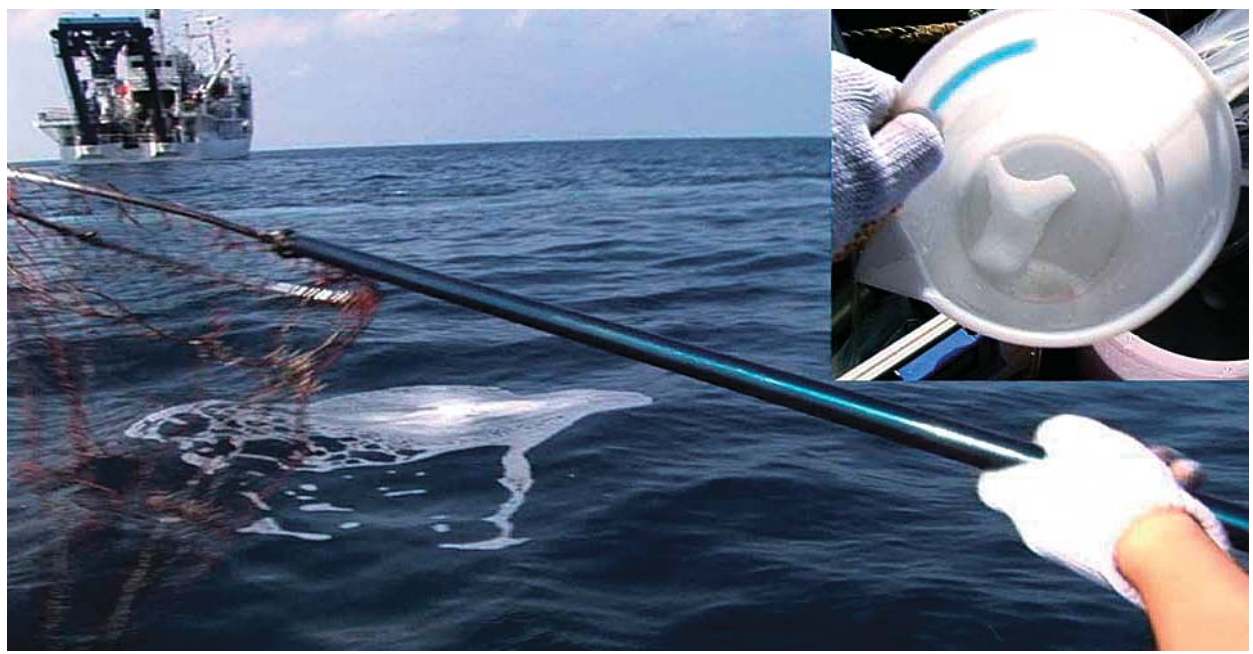

Figure 4: Floating rubble of methane hydrate and recovered specimen of solid hydrate (Upper right). R/V Natsushima is also seen (Upper right). 
